Original Contribution

\title{
EFFECT OF INOCULATION OF PEDIOCOCCUS ACIDILACTICI METABOLITES ON THE MICROBIAL PROFILE OF TURKEY MEAT STORED AT DIFFERENT LOW TEMPERATURE RANGE
}

\author{
I. F. Fadahunsi*, O. P. Adejoh , A. A.Onilude \\ Department of Microbiology, University of Ibadan, Ibadan, Nigeria
}

\begin{abstract}
Studies were carried out to investigate the effect of Pediococcus acidilactici culture on turkey meat product stored at different low temperatures range (refrigeration, chilling, freezing and blast freezing). Six lactic acid bacteria species were isolated from fresh turkey meat sample under different low storage conditions. They were identified as Lactobacillus plantarum, Pediococcus acidilactici, Lactobacillus buchneri, Lactobacillus sake, Lactobacillus curvatus, Lactobacillus brevis. Based on percentage occurrence, Pediiococcus acidilactici was selected for further studies in this work. The result obtained from the inoculation of cell suspension of $P$. acidilactici into the turkey meat sample stored at blast freezing, freezing, chilling and refrigeration conditions revealed that the microbial load decreased in count from 0 day to 28 -th day in all the conditions. The blast freezing had the least while refrigeration had the highest count. Further identification of these micororganisms in the inoculated meat sample under study showed that Staphyloccus aureus occurred most frequently (14\%) and the least was Esherichia coli with $4 \%$. The result of nutritional analysis of the turkey meat sample inoculated with $P$. acidilactici cell suspension and stored for $96 \mathrm{hr}$ showed that the crude protein and thiobarbituric acid decreased by $37.25 \%$ and $54.17 \%$ respectively while the free fatty acid increased by $118 \%$. In conclusion, the turkey meat sample under blast freezing showed the the least microbial load which implies longest shelf life. The blast freezing temperature appears to be the most relatively efficient storage temperature in this study.
\end{abstract}

Key words: Pediococcus acidilactici, blast freezing, freezing, refrigeration, chilling, turkey meat

\section{INTRODUCTION}

Economic losses due to spoilage of meat and meat product constitute major concern to retailers and consumers in Nigeria. The use of lactic acid bacteria for food processing is not only based on their characteristics flavor enhancing nature but more on their ability to lower $\mathrm{pH}$ and to produce antimicrobial agents such as lactic acid, acetic acid, ethanol, diacetyl, hydrogen perioxide, reutrin and bacteriocins $(1,2,3,4)$. In addition to preservation, a number of nutritional, technological and health benefits are associated with the use of LAB fermentation. (5)

*Correspondence to: I. F Fadahunsi, Department of Microbiology, University of Ibadan, Ibadan, Nigeria,

E-mail: sanmifadahunsi@yahoo.com
Lucke (6) reported that this property of Lactic acid bacteria had enhanced stable and safer fermented end- product. Food and feed fermented with lactic acid bacteria have been reported to contain higher vitamins, predigested protein and lactose, absence of phytate and glucosoinolates, anticarcinogenic and hypochlolesterimic activities $(7,8)$.

Meat has long been considered a highly desirable and nutritious food, but unfortunately it is also highly perishable because it provides the nutrients needed to support the growth of many types of microorganisms $(9,10)$ Apart from microbial spoilage some chemical and biochemical changes do occur during prolonged storage and these may reduce the shelf life of the meat (9). Owning to the spoilage potential of meat, many varieties of preservation techniques 
are being employed in improving its keeping quality and shelf life. Such techniques include heating, drying, curing, salting, sugar addition, irradiation and cold temperature storage (9).

Factors affecting meat spoilage include intrinsic (e.g. $\mathrm{pH}, \mathrm{a}_{\mathrm{w}}$, composition, type and extent of initial contamination $\}$ and extrinsic parameters (e.g temperature and packaging atmosphere). Among these, temperature is considered the most important factor because temperatures approaching $0^{\circ} \mathrm{C}$ or lower retard the growth and metabolic activities of microorganisms (11, 5). Today meat preservation is associated with refrigerator, the deep freezer, canning process and blast freezing which is not popularly used in Nigeria (12). Modern refrigeration and freezing equipments have made it possible to transport and store perishable foods for long period of time (5). One of the concern in current food preservation research is the replacement of chemical preservatives due to their harmful side-effects with more natural biopreservative method such as the use of organic acids or the application of fermentation process $(13,14,15)$. Also modern methods include the use of enzyme lysosomes from chicken eggs and membrane-active bacteriocin and nisin (16). Microorganisms represent an excellent source of enzymes owing to their broad biochemical diversity and susceptibility to genetic mutation (17). However, microbes are preferred source of enzymes due to their rapid growth, limited space required for cultivation, ready accessibility to genetic mutation (17). The utilization of freezing, chilling and refrigeration techniques is highly documented. However there is paucity of information regarding the application of blast freezing technique in meat preservation in Nigeria. Therefore, this present work is aimed at studying the efficiency of blast freezing technique in meat storage and preservation.

\section{MATERIALS AND METHODS Collection of Samples}

Turkey meat samples were procured from Ekiti, Oyo and Lagos States in South Western Nigeria. The samples were brought to the laboratory in sterile containers for immediate use.

\section{Isolation procedure}

Five grams of the fresh turkey meat sample was weighed and transferred into $100 \mathrm{ml}$ of sterile distilled water in $250 \mathrm{ml}$ conical flask and this
FADAHUNSI I. F., et al. was vigorously shaken to dislodged the microorganisms present in the sample into the sterile distilled water. Serial dilution of the water extract from the meat sample was carried out according to the method described by Harrigan and McCane (18) and $0.5 \mathrm{ml}$ of dilution $10^{4}$ was transferred into sterile Petri-dishes containing Rogosa and Sharpe (MRS) agar and incubated anaerobically at $37^{\circ} \mathrm{C}$ for $48 \mathrm{~h}$. The plates were examined for growth and the isolates observed were subcultured repeatedly until pure cultures were obtained and stored on MRS slants in Mac Canthney bottles and kept in the refrigerator. The remaining portion of the turkey meat sample was divided into three portions and were subjected separately to blast freezing treatments using blast freezer (50 horse power Presco Model), Freezing using Deep freezer (Ariston Model No 153), refrigeration and chilling using (Haier Thermocool Model No HR - 137) for 28days.

Isolation was carried out again on the turkey meat samples subjected to different low temperature treatments as described earlier at 7days interval for 28days using MRS agar.

\section{Identification procedure}

Pure cultures of the isolate were identified using API 50CH and $50 \mathrm{CHL}$ medium. (API system, Montalieu, Vericeu, France) and percentage occurrence of the LAB isolates was calculated (This procedure had been used in an earlier publication by me)

\section{Preparation of inoculum}

A loop full of a twenty four hours old culture of the LAB isolate with the highest $\%$ of occurrence was transferred into $150 \mathrm{ml}$ Erlenmeyer flask containing $50 \mathrm{ml}$ of sterile MRS broth which was incubated anaerobically at $37^{\circ} \mathrm{C}$ for $48 \mathrm{~h}$.One $\mathrm{ml}$ of the bacterial cells suspension was aseptically inoculated into sterile plate containing MRS agar and incubated anaerobically for $24 \mathrm{~h}$. The number of colonies observed on plate were counted and this serves as the CFU/ML

\section{Inoculation of turkey meat sample}

Another three set of fresh turkey meat samples were obtained and differently inoculated with $1 \mathrm{ml}$ of culture suspension $\left(1.70 \times 10^{4}\right)$ of the LAB isolate showing the highest \% occurrence. The inoculated turkey meat samples were subjected separately to blast freezing, freezing, refrigeration and chilling for 28days. 


\section{Isolation technique}

Isolation of microorganisms from the inoculated turkey meat sample with $1 \mathrm{ml}$ of culture suspension $\left(1.70 \times 10^{4}\right)$ of the LAB isolate showing the highest $\%$ occurrence and subjected separately to blast freezing, freezing, refrigeration and chilling for 28days was carried out as described earlier at 7days interval but Nutrient Agar(NA), Mac Conkey Agar (MC) and Potato Dextrose Agar (PDA) were used and incubation was done aerobically at $30^{\circ} \mathrm{C}$ while incubation periods of $48 \mathrm{~h}$ and 7 days were employed and observed microorganisms on plate were enumerated.

\section{Identification procedure}

The bacterial isolates obtained from the turkey meat samples inoculated with $1 \mathrm{ml}$ of culture suspension $\left(1.70 \times 10^{4}\right)$ of the LAB isolate showing the highest $\%$ occurrence and stored at different low temperatures were identified using API 20E and API 20NE, while the fungal isolates were identified with reference to compendium of soil fungi. (19)

\section{Microbial Treatment of turkey meat sample}

A fresh turkey meat sample (5gms) was obtained and inoculated with $1 \mathrm{ml}$ of culture suspension $\left(1.70 \times 10^{4}\right)$ of the LAB isolate showing the highest \% occurrence and kept at blast freezing temperature for 5 days.

\section{Nutritional Analysis}

Determination of Crude Protein Content, Free Fatty Acid (FFA) and Thiobarbituric Acid (TBA) of fresh turkey meat sample inoculated with $1 \mathrm{ml}$ with of culture suspension $\left(1.70 \times 10^{4}\right)$ of the LAB isolate showing the highest \% occurrence and stored at blast freezing temperature for 5 days were determined according to the method of AOAC (20)

\section{RESULTS}

Table 1 shows percentage occurrence of Lactic acid bacteria isolated from turkey meat samples at different low temperature storage while Table 2 shows microbial load of fresh turkey sample inoculated with culture suspension of Pediococcus acidilactici $(\log c f u)$ and stored at different low temperature storage. Table $\mathbf{3}$ shows the frequency of occurrence of different isolates from turkey meat sample inoculated with Pediococcus acidilactici and stored at different low temperatures. Table 4 shows nutritional analysis of turkey meat sample inoculated with $1 \mathrm{ml}$ of Pediococcus acidilactici cell suspension and stored at blast freezing temperature for 5 days.

Table 1. The Percentage occurrence of Lactic acid bacteria isolated from turkey meat samples

\begin{tabular}{ll}
\hline Isolates & Percentage occurrence \\
\hline Pediococcus acidilactici & 47.2 \\
Lactobac illus plantarum & 35.9 \\
Lactobac illus buchneri & 14.3 \\
Lactobac illus sale & 10.7 \\
Lactobac illus curvatus & 8.3 \\
Lactobac illus brevis & 7.4
\end{tabular}

The result of isolation showed that the highest occurring microorganisms was Pediococcus acidilactici showing (47.2\%), followed by Lactobacillus plantarum (35.9\%) while the least was Lactobacillus curvatus $(7.4 \%)$ a refrigeration, $\mathrm{b}$ chilling, $\mathrm{c}$ freezing, $\mathrm{d}$ blast freezing.

TEK location 1, Ekiti state, TIB location 2,Oyo state, Lagos state TIB location 3,Oyo state.

The turkey meat sample stored at the blast freezing temperature contained the least number of microorganisms, 3.90 at the $28^{\text {th }}$ day while the highest microbial load 5.16 was recorded in turkey meat sample stored at refrigeration temperature at the $28^{\text {th }}$ day.

Further identification of the microbial load to species level in the turkey meat samples under different low temperatures storage (blast freezing, freezing, refrigeration and chilling) showed that Staphyloccus aureus recorded the highest frequency of occurrence with (14\%) while the least occurring microorganism was observed to be Escherichia coli with $4 \%$. 
Table 2. The Microbial load of fresh turkey sample inoculated with $1 \mathrm{ml}$ culture suspension of Pediococcus acidilactici (log cfu) and stored at different low temperatures storage.

\begin{tabular}{|c|c|c|c|c|c|c|c|c|c|c|c|c|}
\hline Duratio & & & & & & OCAI & ION & & & & & \\
\hline (Days) & TEK $^{2}$ & TLA $^{2}$ & $T \mathbb{B B}^{2}$ & TEK $^{6}$ & TL $A^{b}$ & $\mathrm{TIB}^{\mathrm{b}}$ & TEK $^{c}$ & TLA $^{a}$ & $T I B^{c}$ & TEK $^{\delta}$ & TLA ${ }^{\delta}$ & $T 1 B^{d}$ \\
\hline & & 5.2 & & & 4.8 & & 4. & & 5.1 & & & 5.30 \\
\hline & & & & 4.8 & 4. & & 5. & 5. & 5. & & & 4 \\
\hline & & 5.2 & 5. & 4.8 & 4. & & & 5.1 & 5. & & & 4.6 \\
\hline & 5.17 & 5.15 & 5.16 & 4.73 & 4.73 & 4.7 & 5.0 & 5.05 & 5.04 & 5.1 & 5.2 & 4.25 \\
\hline & 5.16 & 5.09 & 5.08 & 4.70 & 4.61 & 4.18 & 4.96 & 4.92 & 4.90 & 4.05 & 3.90 & 4.11 \\
\hline
\end{tabular}

Table 3. The Frequency of occurrence of different isolates from turkey meat sample inoculated with $1 \mathrm{ml}$ cell suspension of Pediococcus acidilactici and stored at different low temperatures.

\begin{tabular}{ll}
\hline Microorganisms & Frequency of occurrence \\
Enterobacteriacea & \\
\hline Pseudomonas putida & 7 \\
Pseudomonas flourescens & 7 \\
Klebsiella pneumoniae & 11 \\
Enterobacter aerogenes & 6 \\
Eschericia coli & 4 \\
Proteus mirabilis & 9 \\
Gram Positive Organisms & \\
Micrococcus species & 9 \\
Staphylococcus species & 14 \\
Bacillus substilis & 7 \\
Bacillus cereus & 5 \\
Fungi & \\
Aspergillus niger & 11 \\
Aspergillus flavus & 6 \\
Rhizopus stolononifer & 6 \\
Penicillium notatum & 5 \\
\hline
\end{tabular}

Table 4. Nutritional analysis of turkey meat sample inoculated with $1 \mathrm{ml}$ of Pediococcus acidilactici cell suspension and stored at blast freezing temperature for 5 days.

CP(\%) $\quad$ FFA(\%) TBA(mg/malonaldehyde/kg)

\section{Storage Period (h)}

\begin{tabular}{llll}
\hline 0 & 70.44 & 0.30 & 0.48 \\
24 & 65.60 & 0.42 & 0.42 \\
48 & 63.10 & 0.50 & 0.36 \\
72 & 52.50 & 0.50 & 0.32 \\
96 & 51.40 & 0.54 & 0.28 \\
120 & 44.20 & 0.60 & 0.22 \\
\hline
\end{tabular}


The proximate analysis of the turkey sample inoculated with $1 \mathrm{ml}$ cell suspension of Pediococcus acidilactici and stored under blast freezing temperature for 5days is shown in Table 4. The crude protein content was higher in the control when compared with the treated turkey meat sample. It was observed that it decreased from 70.44 to 44.00 at the 5day, while fatty acid content increased from 0.30 to 0.60 within the same period. However the thiobabituric acid showed a decrease of $118 \%$ after $120 \mathrm{hr}$.

\section{DISCUSSION}

Determination of percentage occurrence of Lactic acid bacteria isolated from turkey meat samples at different low temperature storage, determination of microbial load of fresh turkey samples inoculated with culture suspension of Pediococcus acidilactici and stored at different low temperature storage, determination of the frequency of occurrence of different isolates from turkey meat sample inoculated with Pediococcus acidilactici and stored at different low temperature and determination of nutritional analysis of turkey meat sample inoculated with $1 \mathrm{ml}$ of Pediococcus acidilactici cell suspension and stored at blast freezing temperature for 5 days were carried out. Table 1 shows percentage occurrence of Lactic acid bacteria isolated from turkey meat samples at different low temperature storage. The LAB species isolated from fresh turkey meat samples under low different temperature storage were identified as Pediococcus acidilactici, Lactobacillus plantarum, Lactobacillus buchneri, Lactobacillus sake, Lactobacillus curvatus and Lactobacillus brevis, Hamasaki et al (21) and Kato et al (22) had previously reported the isolation of $L$. plantarum and $P$. acidilactici from spoiling cooked meat stored at $10^{\circ} \mathrm{C}$ while Stiles (9) had identified aciduric Lactobacillus spp including $L$. sake, L. curvatus and L. plantarum from fresh meat samples.. The survival of LAB especially in cold turkey meat sample could be due to the substrate uptake, cell permeability, enzyme systems and synthetic pathway which are able to function at psychrophilic temperature (23). However, the nutritious nature of meat makes it to be susceptible to microbial growth and proliferation because it provides the nutrients needed to support the growth of many types of microorganisms (9)

Table 2 shows microbial load of fresh turkey sample inoculated with $1 \mathrm{ml}$ culture suspension
FADAHUNSI I. F., et al. of Pediococcus acidilactici and stored at different low temperatures storage. The decrease in microbial load observed in the turkey meat samples inoculated with culture suspension of $\mathrm{P}$ acidilactici may be due to the production of antimicrobial compounds such lactic acid, diacetyl, hydrogen peroxide and bacteriocin which had been reported to be secreted by the administered microorganism and these create a high inhibitory ability to other invading microorganism (1).

However, the viable counts of microorganisms at blast freezing temperature was observed to be the least while the refrigeration temperature recorded the highest. This observation explains the spoilage of meat vis-à-vis growth of microorganisms. During refrigeration treatment, increase in viable count led to meat spoilage. Brackett (24) reported that refrigeration treatment is primarily a surface phenomena resulting in the formation of slime and off odour. Spoilage of fresh meat at refrigeration temperature is a problem of aesthetics, product quality and economics (25).

Table 3 shows the frequency of occurrence of different isolates from turkey meat sample inoculated with $1 \mathrm{ml}$ cell suspension of Pediococcus acidilactici and stored at different low temperatures. The presence of spoilage microorganisms in meat preserved under cold storage conditions had earlier been reported (22).

The presence of Klebsiella pneumoniae, Proteus mirabilis, Enterobacter aerogenes, Escherichia coli, Pseudomonas putida, Pseudomonas flourescens, Bacillus subtilis, Bacillus cereus, Aspergillus niger, Rhizopus stolonifer, Aspergillus flavus and Penicillium notatum in turkey meat samples inoculated with culture suspension of P.acidilactici might be caused by the selective limitation of the antibactericidal and antifungicidial activities of the metabolites produced by P.acidilactici and this might be responsible for the existence of these microorganisms with different $\%$ of occurrence. In addition, the differences in the level of the microbial load of different turkey meat samples stored under the same temperature regime might be caused by contamination of raw product, sanitation in the processing plant and the speed and care within which the product was processed in their different locations of procurement (26) 
Table 4 represents nutritional analysis of turkey meat sample inoculated with $1 \mathrm{ml}$ of Pediococcus acidilactici cell suspension and stored at blast freezing temperature for 5days. The decrease in crude protein content of the turkey meat sample could be due to proteolytic activities of the inoculated $P$. acidilactici and other microbes during storage (9), while the increase in free fatty acid could be explained as a result of citrate metabolism by some species of LAB thus enhancing FFA production (27). However the decrease in thiobarbituric acid production is an indication of microbial safety/stability of the meat product. It can therefore be deduced that turkey meat sample will be most microbiologically stable under blast freezing temperature than other temperature storage reported in this study.

\section{CONCLUSION}

From this investigation blast freezing storage coupled with the application of Pediococcus acidilactici metabolite seemed to be the most efficient technique in preserving meat product.

\section{REFERENCES}

1. Balcazar, J. L.; de Bias, I.; Ruiz-Zarzuela, I.; Vendrell, D.; Girones, O.; Muzquiz, J. C., Sequencing of variable regions of the $16 \mathrm{~S}$ rRNA gene for identification of lactic acid bacteria isolated from the intestinal microbiota of healthy salmonids. Comparative Immunology Microbiology Infectious Diseases 30, 111-118, 2007.

2. De Vuyst, L.; Callewaert, R.; and Crabbe, K. 1996. Primary metabolic kinetics of bacteriocin biosynthesis by Lactobacillus amylovorus and evidence for stimulation of bacteriocin production under unfavourable growth condition. Microbiology 142: 81727.

3. Andrighetto, C., Zampese, L. and Lombardi. A., RAPD-PCR characterization of lactobacilli isolated from artisanal meat plants and traditional fermented sausages of Veneto region (Italy). Lett. Appl Microbiol, 33:130-136 33: 36-30, 2001.

4. Adeniyi, B.A., Ayeni, F.A. and Ogunbanwo, S.T. Antagonistic activities of lactic acid bacteria isolated from Nigerian fermented dairy food against organisms implicated in urinary tract infection. Journal of Biotechnology 5:2:183-188, 2006.
FADAHUNSI I. F., et al.

5. Koutsounmanis, K., Starnatious, A., Skandarnis, P. \& Nychas, G.J.E. Development of a microbial model for the combined effect of temperature and $\mathrm{pH}$ on spoilage of ground meat, and validation of the model under dynamic temperature conditions. Applied environmental Microbiology, 72: 124-134, 2006.

6. Lucke, F.K., Utilization of microbes to process and preserve meat. Meat Science. 56: 105-115, 2000.

7. Kalalou, I., Faid, M. and Ahami, A.T., Extending the shelf life of fresh minced camel meat at ambient temperature by Lactobacillus delbruekii sub sp delbruekii. Electronic Journal of Biotechnology. 7: 246 - 251, 2004.

8. Afolabi, R.O., Bankole, O.M and Olaitan, J. O., Production and characterization of antimicrobial agents by lactic acid bacteria isolated from fermented foods. The International Journal of Microbiology.4:2, 2008.

9. Stiles, M.E., Biopreservation by lactic acid bacteria. Antonie Leeuwenhoek 70: 331 345,996 .

10.Ellis, D.I., Broadhurst, D., Kell, D.B., Rowland J.J. and Goodacre, R., Rapid and Quantitative Detection of the Microbial Spoilage of Meat by Fourier Transform Infrared Spectroscopy and Machine Learning. Applied and Env. Microbiology. 68:2822-2828, 2002.

11.Jay, J.M., Vilani, J.P. and Hughes, M.E., Profile and activity of the bacterial biota of ground beef held from freshness to spoilage at 5-7"C. Int. J. Food Microbiol 81: 105 -111, 2003.

12.Prescott, L. M., Hardley, J.P. and Klein, D. A., Microbiology (6th Edition). Mc Graw Hill Publisher New York ,2005

13.Milani, L.I.G., Fries, L.I.M., Boeira, L.S., Melo, V. and Terra, N.N., Bioprotection of frank furter sausages. ActaAlimentaria 27:3:221-229, 1998.

14.Davidson, P.M., Chemical preservatives and naturalantimicrobial compounds. In "Food Microbiology: Fundamentalsand Frontiers," ed. M.P. Doyle, L.R. Beuchat, and T.J. Montville, 2nd ed. ASM Press, Washington, D.C. pp. 593-627, 2001.

15.Riley, M.A. and Wertz, J.E., Bacteriocins: Evolution, ecology, and application. Annual ReviewMicrobiology 56: 117-137, 2002. 
16.Savadogo, A., OuattaraCheik, A.T., BassoleImael, H.N., Traore, S.A., Bacteriocins and lactic acid bacteria.African Journal of Biotechnology5:9: 678-683, 2006

17.Mala, B.R., Aparna, M. T., Mohini, S.G. and Vasant, V. D.,. Molecular and Biotechnology aspects of Microbiol and Mol.Biol. Rev. 62: 597-635, 1998.

18.Harrigan,W.F. and McCance, M.E., Laboratory methods in microbiology. Academy press, London, 342, 1966.

19.Funder, S., Practical Mycology Manual for identification of fungi A.W. Btiskers Boktken. A London way. Dolman 1929 Economic Microbiology of Fermented Food 1961.

20.A.O.A.C., Official Methods of Analysis, $15^{\text {th }}$ edition Washington, DC: Association of official analytical chemists. ISBN $0-93$ $558442-0,2003$

21.Hamasaki, Y., Ayaki, M., Fuchu, H. and Sugiyama, M., Behaviour of psychrotrophic lactic acid bacteria isolated from spoiling cooked meat products. Appl.and Environ. Microbiol. 69: 3668 - 3671, 2003.

22.Kato, Y., Salaka, R.M., Hayashidani, H., Kluchi, A., Kaneuchi, C. and Ogawa, M.,
FADAHUNSI I. F., et al. Lactobacillus algidus a psychroiphilic lactic acid bacterium isolated from vacuumpackaged refrigerated beef. International J. of Systematic and Evolutionary Microbiol. 50: 1143 - 1149, 2002.

23.Cousin, M.A., Jay, J.M. and Varsavada, P.C., Psychrophilic microorganism: A Review. J. Food Prot. 45: 172 - 175, 1982.

24.Barackett, R.E.,Microbiological consequences of minimally processed fruits and vegetables. J. Food. Qual. 10: 195, 1987.

25.Corlett, D.A., Refrigerated foods and use of hazard analysis and critical point principles. Food Technol. 43(2): 91, 1989.

26.Pelzar M.J., Chan, E.C.S. and Kreig, N.R., Microbiology $5^{\text {th }}$ ed., TATA McGraw -Hill Publishing Company Ltd. New Delhi, 1986.

27.Artiasaran, I. , Villanueva, R. and Bello, J. Analysis of proteolysis and protein insolubility during the manufacture of some varieties of dry sewage. Meat Sci. 28:111$127,1990$. 